\title{
MAPPING GREENHOUSE GAS EMISSIONS AND REMOVALS FROM THE LAND USE, LAND USE CHANGE, AND FORESTRY SECTOR AT THE LOCAL LEVEL
}

\author{
G. H. Mitri *, J. Karam \\ Land and Natural Resources Program, Institute of the Environment, University of Balamand, Kelhat, El Koura, Lebanon - \\ george.mitri@balamand.edu.lb
}

\begin{abstract}
KEY WORDS: Greenhouse gas emissions/removals, Land Use, Land Use Change, Forestry, Geographic Object-Based Image Analysis
\end{abstract}

\begin{abstract}
:
Greenhouse gas (GHG) emissions resulting from the Land Use, Land-Use Change, and Forestry sector (LULUCF) are estimated and reported in National Communications to the United Nations Framework Convention on Climate Change (UNFCCC). By definition, the LULUCF sector is a "greenhouse gas (GHG) inventory sector that covers emissions and removals of greenhouse gases resulting from direct human-induced land use, land-use change and forestry activities". In principle, the annual GHG national inventory should be transparent, consistent, comparable, complete, and accurate. Also, it should be able to systematically account for all changes in land use and forest cover over many years. In this context, it is essential to investigate the development of an automated approach for mapping local GHG emissions/removals from the LULUCF sector for integration at the national level. In view of that, the aim of this work was to develop a semi-automated model for estimating GHG emissions and removals form the LULUCF sector at the local level. The specific objectives were to 1) map changes in land use and forest cover between two consecutive years, and 2) assess GHG emissions and removals from the LULUCF sector. The methodology of work comprised the use of Geographic ObjectBased Image Analysis (GEOBIA) for modelling changes in the LULUCF sector and, subsequently, estimating GHG emissions/removals between two consecutive years. The combined use of Very High Resolution (VHR) SPOT imagery (2.5 m colour) and field data was involved in identifying and mapping land-use changes between 2014 and 2015. Subsequently, GHG emissions and removals were estimated using customized features in GEOBIA and following the 2003 Intergovernmental Panel on Climate Change "Good Practice Guidance for Land Use, Land-Use Change and Forestry", which adopts a land use category-based approach to estimate emissions/removals from all land categories and all relevant GHGs. An accuracy assessment of the initial classification was conducted with the use of reference data. The overall classification accuracy of the LULUCF mapping in 2014 was found to be 83\%, while the Kappa Index of Agreement (KIA) was 0.74. The developed GEOBIA model estimated for the year 2015 net annual GHG removals of $-1.613 \mathrm{Gg}$ of $\mathrm{CO} 2$ eq. (i.e., an approximate increase of $12.7 \%$ in removals between 2014 and 2015 ). Future work will involve further development of the model to account for all possible changes in the LULUCF sector and test the transferability of the model to other sites.
\end{abstract}

\section{INTRODUCTION}

Any process, activity, or mechanism, which removes a greenhouse gas from the atmosphere, is referred to as a sink under the United Nations Framework Convention on Climate Change (UNFCCC). Human activities can impact terrestrial sinks, through land use, land-use change and forestry (LULUCF) activities (Houghton et al., 2003; Watson et al., 2000). Accordingly, UNFCCC invited the Intergovernmental Panel on Climate Change (IPCC) to develop good practice guidance for LULUCF to assist countries in producing inventories for the land use, land-use change and forestry sector. As a result, the report on Good Practice Guidance for Land Use, Land-Use Change and Forestry (GPG-LULUCF) was developed to provide methods and good practice guidance for estimating, measuring, monitoring and reporting on carbon stock changes and greenhouse gas emissions from LULUCF activities under Article 3, paragraphs 3 and 4, and Articles 6 and 12 of the Kyoto Protocol (IPCC, 2003).

The annual GHG national inventory should be transparent, consistent, comparable, complete, and accurate. Also, it should be able to account all local changes in land use and forest cover. Accordingly, GPG-LULUCF describes three approaches for representing land areas (IPCC, 2003). Approach 1 identifies the total area of each individual land-use category, but does not provide detailed information on changes of area between categories and is not spatially explicit. Approach 2 introduces tracking of land-use changes between categories, while approach 3 extends approach 2 by allowing land-use changes to be tracked on a spatial basis. More specifically, the study area in approach 3 is subdivided into spatial units such as polygons appropriate to the scale of land-use variation. The spatial units must be utilized consistently over time and should be sampled using pre-existing map data with either a Geographic Information System (GIS) and/or in the field. Furthermore, observations may be acquired from satellite imagery, field visits, or questionnaires.

In this context, the use of objects (instead of pixels) that can facilitate the usage of, not only spectral, but also contextual and spatial information, considering the shape and texture of objects, as well as topological features (neighbour, superobjects, etc.) would be essential to be adopted in approach 3 .

\footnotetext{
* Corresponding author
} 
Geographic Object-Based Image Analysis (GEOBIA) has been devoted to developing automated methods of partitioning highresolution, remote-sensing imagery into meaningful imageobjects, and assessing their characteristics (Blaschke, 2010). GEOBIA of optical satellite data, ranging from low to very high spatial resolution, has been successfully used in several studies for mapping vegetation characteristics (Mitri et al., 2015; Mitri and Gitas, 2004) and landcover/land-use (Goodin et al., 2015). Based on the above, it would be worth exploring the capability of GEOBIA for the generation of time series of LULUCF area maps with the use of multi-temporal satellite imagery and field data acquisitions.

Previous national inventory reports (MoE/UNDP/GEF, 2011; $\mathrm{MoE} / \mathrm{UNDP}$, 1999) in Lebanon addressed GHG emissions/removals from the LULUCF sector mostly based on basic land-use data (i.e., tier 1 approach). Most recently, Lebanon's National GHG inventory for LULUCF involved the use of GEOBIA by employing multi-temporal satellite images for mapping specific changes in the landcover/land-use areas between consecutive years (MoE/UNDP/GEF, 2015). However, the automation of the process for mapping and assessing GHG emissions/removals was found to be essential in such analysis especially when the inventory covers an extensive multitemporal analysis of LULUCF. Accordingly, the aim of this work was to develop a semi-automated model for estimating GHG emissions and removals form the LULUCF sector at the local level. The specific objectives were to 1) map changes in land use and forest cover between two consecutive years, and 2) assess GHG emissions and removals from the LULUCF sector.

Data at fine scale, however, could directly account for units of land on which afforestation, reforestation or deforestation has occurred. Also, data available from satellite remote sensing can be combined with ancillary data to improve the accuracy of land-use classification.

\section{STUDY AREA AND DATASET DESCRIPTION}

\subsection{Study area}

The study area is the administrative area of Mounjiz (343' $\mathrm{N}$ and $36^{\circ} 14^{\prime}$ E) located in the north of Lebanon. The elevation ranges from $290 \mathrm{~m}$ to $350 \mathrm{~m}$ above sea level. Mounjiz has a population of 557 permanent inhabitants, counting 121 households. The surface of Mounjiz is 594 hectares, out of which 154 hectares are agricultural lands mainly consisting of vineyards and olive groves, and 39.2 hectares are occupied by a mixed forest of laurel trees (Laurus nobilis) and oaks (Quercus sp.). A total of ten hectares of grasslands were afforested in the year 2015 with stone pine (Pinus pinea), bay laurel (Laurus nobilis) and fruitful carob (Ceratonia silica) seedlings. The study area has a Mediterranean climate, which is characterized by mild rainy winters mainly between October and March, and hot dry summers between June and September. The registered mean annual precipitation is between $800-900 \mathrm{~mm}$ with an average number of 77 days of rain per year. The mean annual temperature is around $20^{\circ} \mathrm{C}(\mathrm{MOE} / \mathrm{UNDP}, 2011)$.

\subsection{Dataset description}

Satellite imagery namely SPOT ( $2.5 \mathrm{~m}$ colour) acquired on 15 9-2011 was collected. In addition, frequent field visits were conducted in 2014 and 2015 to survey the location and extent of afforested areas. A shapefile of afforested areas in 2015 was also employed. Field data observations of afforested areas comprised an exhaustive counting of planted seedlings, their survival rate, and their growth performance. Information about field wood gathering, estimated in 2014 at 80 tonnes, was collected from personal communications with the Municipality of Mounjiz.

\section{METHODOLOGY}

The methodology of work comprised the use of GEOBIA for mapping changes in the LULUCF sector and, subsequently, estimating GHG emissions/removals between two consecutive years, namely 2014 (i.e., reference year) and 2015. Ideally, changes in LULUCF between year 1 and year 2 are mapped using satellite images acquired on different dates, respectively. This approach was previously tested and adopted at the national level using spectral features from a series of Landsat Thematic Mapper images (MoE/UNDP/GEF, 2015).

In this work, Very High Resolution (VHR) SPOT imagery (2.5 $\mathrm{m}$ colour) was used in combination with field observations for mapping landcover/land-use in 2014. Changes in LULUCF between 2014 and 2015 were identified and mapped with the use of a shapefile produced from field data collection.

Consequently, GHG emissions and removals were estimated using customized features in GEOBIA and following the GPGLULUCF, which adopts a land-use category-based approach to estimate emissions/removals from all land categories and all relevant GHGs.

\subsection{Classification scheme}

The top-level land categories which were considered in the mapping were the following (IPCC, 2003): Forest land (F), Cropland (C), Grassland (G), Wetland (W), Settlement (S) and Other land (O). The abbreviations FF, CC, GG, WW, SS, OO denoted land-use categories undergoing no conversions; and the abbreviations LF, LG, LC, LW, LS, LO denoted land conversions to these land-use categories.

The inventory of year 2014 was considered a reference year and the areas extracted from the classification of the land cover/land use in 2014 were considered as reference values.

\subsection{GEOBIA}

The methodology of work involved 1) creating a classification scheme based on previously discussed land categories, 2) generating image objects or segments for subsequent classification, and 3) mapping the different land use and landuse change categories. The GEOBIA approach was adopted by employing the software "eCognition". More specifically, GEOBIA comprised two steps, namely, segmentation and classification of segmented images.

First, the segmentation of the VHR SPOT imagery at the pixels level was generated by using an average abstract scale of 10 and equal band weights. In general, the composition of homogeneity criterion included the following weights: $10 \%$ for shape, $90 \%$ for colour, and $50 \%$ for compactness. These same parameters were used to create two different levels of image segmentation, namely level 1 and level 2.

The land-use categories in 2014 were classified at level 1 using mainly layer mean values of the SPOT imagery (Figure 1). The 
classification was refined with the employment of land-use data collected in the field.

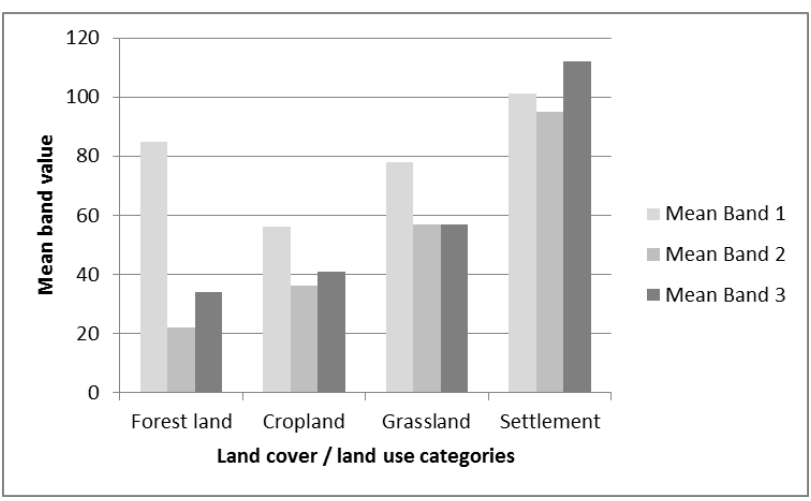

Figure 1. Mean band values per landcover/land-use categories

Changes in LULUCF in 2015 were classified at level 2. This incorporated mainly contextual features such as "existence of sub-objects" to classify conversion/non-conversion of lands. Field observations showed no significant changes (i.e., conversion of lands) other than the afforested areas. This was mainly attributed to the small size of the study area, the limited timeframe, and the location of the site in a rural area experiencing very little development. The feature "thematic object attribute" was used to classify afforested areas (i.e., objects) based on the employed shapefile of field-based data.

\subsection{Emission/removal factors}

Collection of the Emission/Removal (E/R) factors was done following two methodologies taking into account the availability and type of data (IPCC, 2003):

- Tier 1: IPCC GPG Default assumptions

- Tier 2: local data from surveys, and personal communications

Accordingly, customized features based on IPCC (2003) equations were built in "eCognition" for each of the following land-use categories: FF, CC, LF. Other land use categories are not reported as per GPG-LULUCF (IPCC, 2003). The summary equation, which estimates the annual emissions or removals from FF with respect to changes in carbon pools is given in Equation 1:

$\Delta \mathrm{C}_{\mathrm{FF}}=\left(\Delta \mathrm{C}_{\mathrm{FFLB}}+\Delta \mathrm{C}_{\mathrm{FFDOM}}+\Delta \mathrm{C}_{\mathrm{FFS} \text { oils }}\right)$

Equation 1

Where:

$\Delta \mathrm{CFF}_{\mathrm{FF}}=$ annual change in carbon stocks from forest land remaining forest land, tonnes ${\mathrm{C} \mathrm{yr}^{-1}}^{-1}$

$\Delta \mathrm{CFFLB}_{\mathrm{F}}=$ annual change in carbon stocks in living biomass (includes above- and belowground biomass) in forest land remaining forest land; tonnes $\mathrm{C} \mathrm{yr}^{-1}$

$\Delta$ CFFDOM $=$ annual change in carbon stocks in dead organic matter (includes dead wood and litter) in forest land remaining forest land; tonnes $\mathrm{C} \mathrm{yr}^{-1}$

$\Delta$ CFFSoils $=$ annual change in carbon stocks in soils in forest land remaining forest land; tonnes ${\mathrm{C} \mathrm{yr}^{-1}}^{-1}$

The summary equation, which estimates the annual change in carbon stocks in $\mathrm{CC}$ is given in Equation 2:
Where:

$\Delta \mathrm{C}_{\mathrm{CC}}=$ annual change in carbon stocks in cropland remaining cropland, tonnes $\mathrm{C} \mathrm{yr}^{-1}$

$\Delta \mathrm{C}_{\mathrm{CCLB}}=$ annual change in carbon stocks in living biomass, tonnes $\mathrm{C} \mathrm{yr}^{-1}$

$\Delta \mathrm{C}_{\mathrm{CCS} \text { oils }}=$ annual change in carbon stocks in soils, tonnes $\mathrm{Cyr}^{-1}$

Finally, the summary equation, which estimates the annual emissions or removals from LF with respect to changes in carbon pools is given in Equation 3:

\section{$\Delta \mathrm{C}_{\mathrm{LF}}=\Delta \mathrm{C}_{\mathrm{LFLB}}+\Delta \mathrm{C}_{\mathrm{LFDOM}}+\Delta \mathrm{C}_{\mathrm{LFS}}$ oils $\quad$ Equation 3}

\section{Where:}

$\Delta \mathrm{C}_{\mathrm{LF}}=$ annual change in carbon stocks in land converted to forest land, tonnes $\mathrm{C} \mathrm{yr}^{-1}$

$\Delta \mathrm{C}_{\mathrm{LFLB}}=$ annual change in carbon stocks in living biomass (includes above- and belowground biomass)

in land converted to forest land; tonnes $\mathrm{C} \mathrm{yr}^{-1}$

$\Delta \mathrm{C}_{\mathrm{LFDOM}}=$ annual change in carbon stocks in dead organic matter (includes dead wood and litter) in land converted to forest land; tonnes ${\mathrm{C} \mathrm{yr}^{-1}}^{-1}$

$\Delta \mathrm{C}_{\mathrm{LFSoil}} \mathrm{S}=$ annual change in carbon stocks in soils in land converted to forest land; tonnes ${\mathrm{C} \mathrm{yr}^{-1}}^{-1}$

\subsection{Accuracy assessment}

Mapping accuracy was assessed by means of ground-reference data. Accordingly, accuracy assessment of the initial classification was conducted with the combined use of field observations and VHR satellite data. Stratified random sampling was applied using the ERDAS Imagine software. A total of 30 points were randomly generated and checked for classification accuracy using field observations and visual interpretation of the VHR satellite imagery.

\section{RESULTS AND DISCUSSION}

The classification results at level 1 (Figure 2) showed the following coverage percentage: settlement/urban (3.37\%), grassland $(58.9 \%)$, forest land $(11.78 \%)$, and cropland $(25.92 \%)$.

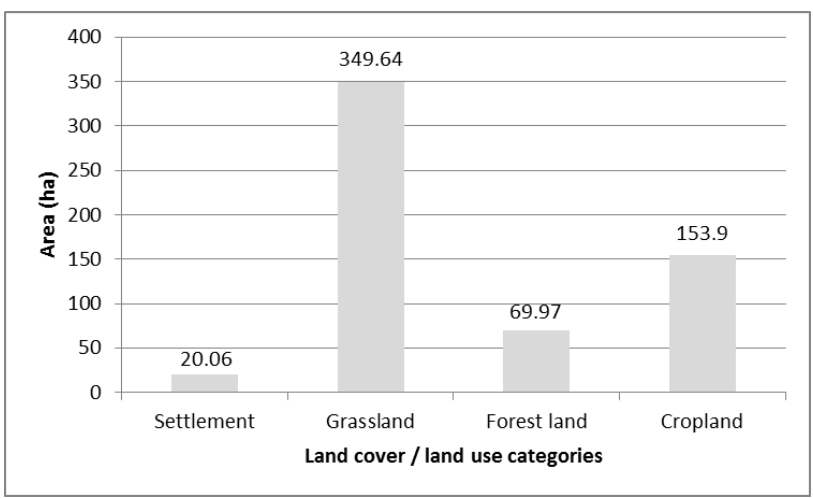

Figure 2. Areas of classified landcover/land-use categories at level 1 
The overall classification accuracy of the LULUCF mapping in 2014 was found to be $83 \%$, while the Kappa Index of Agreement (KIA) was 0.74. Main confusions were observed between the classes "Cropland" and "Grassland". This was mainly due to many agricultural lands being abandoned and vice versa.

The classification results at level 2 (Figure 3) indicated a total area of 10 ha classified as LF. More specifically, it was observed that these 10 ha of lands represented grassland areas, in the year 2014, converted to a forest land in 2015.

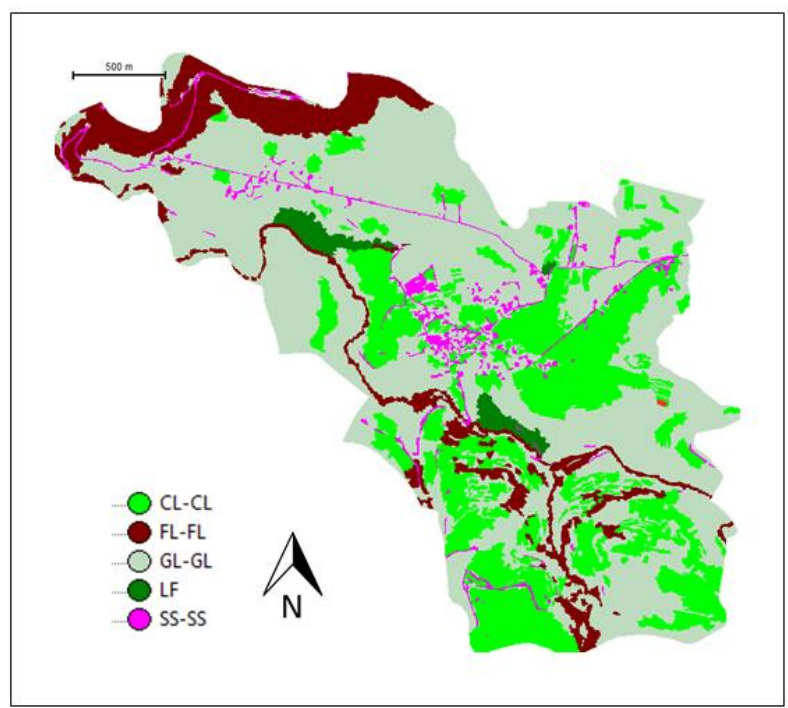

Figure 3. Classified map at level 2

Accordingly, the produced landcover/land-use statistics were used for assessing GHG emissions/removals in 2015 (Table 1).

\begin{tabular}{|l|l|}
\hline $\begin{array}{l}\text { Land-use categories undergoing either no } \\
\text { conversion or conversion between 2014 and 2015 }\end{array}$ & $\begin{array}{l}\text { Area } \\
\text { (ha) }\end{array}$ \\
\hline Forest land remaining forest land (FF) & 69.97 \\
\hline Grassland remaining grassland (GG) & 339.64 \\
\hline Cropland remaining cropland (CC) & 153.9 \\
\hline Settlement remaining settlement (SS) & 20.06 \\
\hline Grassland converted to forest land (LF) & 10 \\
\hline Total & 593.57 \\
\hline
\end{tabular}

Table 1. Changes in Land-use areas

The classified map was exported by integrating the previously build customized features for estimating GHG emissions/removals in each image object. As a result, the share of $\mathrm{CO}_{2}$ removals in 2014 was automatically calculated as follows: $-0.494956 \mathrm{Gg}$ of $\mathrm{CO}_{2}$ eq. (FF) and $-0.91245 \mathrm{Gg}$ of $\mathrm{CO}_{2}$ eq. (CC). The developed GEOBIA model estimated for the year 2015 net annual GHG removals of $-1.613 \mathrm{Gg}$ of $\mathrm{CO}_{2}$ eq. (i.e., an approximate increase of $12.7 \%$ in removals between 2014 and 2015).

\section{CONCLUSIONS}

In this work, changes in land use and forest cover between two consecutive years were mapped using the GEOBIA approach. Accordingly, GHG emissions/removals were automatically calculated with the use of emissions/removals equations that were integrated in the model. The semi-automated model is expected to provide a basic tool for potential use in the development of national inventory reports for estimating GHG emissions/removals from the LULUCF sector especially by allowing land-use changes to be tracked on a spatial basis. However, future work will include an extensive development of the model by 1) using multi-temporal satellite imagery of a larger area for mapping changes/no changes in landcover/land use, and 2) integrating additional customized features to address all possible land-use categories undergoing either conversion or non-conversion of lands.

\section{ACKNOWLEDGEMENTS}

This work was conducted within the framework of the ARDAC project (2014-2018), financed by the European Union, managed by the Lebanese Ministry of Agriculture and implemented by the University of Balamand in partnership with the Municipality of Mounjiz. The contents of this publication are the sole responsibility of the University of Balamand and can in no way be taken to reflect the views of the European Union.

\section{REFERENCES}

Blaschke, T., 2010. Object based image analysis for remote sensing, International Journal of Photogrammetry and Remote Sensing, 65, pp. 2-16.

Goodin, D., Anibas, K., and Bezymennyi, M. 2015. Mapping land cover and land use from object-based classification: an example from a comlex agricultural landscape. International journal of Remote Sensing, 36(18), pp. 4702-4723.

Houghton, R. A., and J. L. Hackler, 2003. Sources and sinks of carbon from land-use change in China, Global Biogeochemical Cycles, 17, 1034, doi:10.1029/2002GB001970.

IPCC, 2003. Good Practice Guidance for Land Use, Land-Use Change and Forestry (Edit. Penman et al.). Institute for Global Environmental Strategies (IGES) for the Intergovernmental Panel on Climate Change (IPCC), Kanagawa, Japan.

Mitri, G., and I. Gitas, 2004. A semi-automated object-oriented model for burned area mapping in the Mediterranean region using Landsat-TM imagery, International Journal of Wildland Fire. 13(3):367-376.

Mitri, G., Jazi, M., McWethy, D. 2015 Assessment of wildfire risk in Lebanon using Geographic Object-based image analysis. Photogrammetric Engineering \& Remote Sensing, 81(6), pp. 499-506.

MoE/UNDP, 2011. State and Trends of the Lebanese Environment (SOER) 2010, Beirut, Lebanon.

MoE/UNDP, 1999. Lebanon's Initial National Communication under the United Nations Framework Convention on Climate Change. Beirut, Lebanon.

MoE/UNDP/GEF, 2015. National Greenhouse Gas Inventory Report and Mitigation Analysis for the Land Use, Land-Use Change and Forestry Sector in Lebanon. Beirut, Lebanon.

MoE/UNDP/GEF, 2011. Lebanon's Second National Communication to the United Nations Framework Convention on Climate Change. Beirut. Lebanon.

Watson, R. T., Noble, I. R., Bolin, B. et al., 2000. Land use, land-use change, and forestry, Special Report of the IPCC, Cambridge University Press, 377, Cambridge, UK. 